\title{
Fabrication of Coated-Collagen Electrospun PHBV Nanofiber Film by Plasma Method and Its Cellular Study
}

\author{
Jafar Ai, ${ }^{1}$ Saeed Heidari K, ${ }^{2}$ Fatemeh Ghorbani, ${ }^{3}$ Fahimeh Ejazi, ${ }^{3}$ Esmaeil Biazar, ${ }^{4}$ \\ Azadeh Asefnejad, ${ }^{3}$ Khalil Pourshamsian, ${ }^{4}$ and Mohamad Montazeri ${ }^{5}$ \\ ${ }^{1}$ Department of Tissue Engineering, Faculty of Advanced Technologies, Tehran University of Medical Sciences, Tehran, Iran \\ ${ }^{2}$ Clinical Proteomics Research Center, Faculty of Paramedical Sciences, Shahid Beheshti University of Medical Sciences, Tehran, Iran \\ ${ }^{3}$ Department of Biomaterial, Faculty of Biomedical Engineering, Science and Research Branch-Islamic Azad University, Tehran, Iran \\ ${ }^{4}$ Department of Chemistry, Islamic Azad University-Tonekabon Branch, Tonekabon, Iran \\ ${ }^{5}$ Faculty of Medical Sciences, Babol University of Medical Sciences, Iran
}

Correspondence should be addressed to Esmaeil Biazar, e.biazar@tonekaboniau.ac.ir

Received 22 February 2011; Accepted 1 March 2011

Academic Editor: Daxiang Cui

Copyright () 2011 Jafar Ai et al. This is an open access article distributed under the Creative Commons Attribution License, which permits unrestricted use, distribution, and reproduction in any medium, provided the original work is properly cited.

Background. Tissue engineering is defined as the designing and engineering of structures to rebuild and repair a body damaged tissue. Scaffolding Poly Hydroxy Butyrate Valerate (PHBV) has shown good biocompatibility and biodegradable properties. Nanofibers have improved the performance of biomaterials, and could be considered effective. One of the important methods for designing nanofiber scaffold is the electrospinnig method. In this study, PHBV nanofibers were well designed and then, modified with the immobilized collagen via the plasma method. The samples were evaluated by ATR-FTIR, SEM, contact angle, and, finally, cell culture. Results. ATR-FTIR structural analysis showed the presence of collagen on the nanofiber surfaces. The SEM images showed the size average of nanofibers as to be about $280 \mathrm{~nm}$; that increased with a collagen coating up to $300 \mathrm{~nm}$. Contact angle analysis showed 67 degree for uncoated nanofibers and 56 degree for coated nanofibers. Cellular investigations (USS cells) showed better adhesion and cell growth and proliferation of coated samples than uncoated samples. Conclusions. In this work, the PHBV nanofibers with a size average about $280 \mathrm{~nm}$ were designed. Nanofibers were successfully coated with collagen via the plasma methods. These collagen-coated nanofibers could be used well for tissue engineering.

\section{Introduction}

Poly Hydroxy Butyrate Valerate (PHBV) is a biomaterial that is used in a variety of applications including surgical sutures, wound dressing, drug delivery, and tissue engineering. This is due to its specific properties such as good biocompatibility, biodegradability, and nontoxicity as well as its piezoelectricity features. However, this material is a hydrophobic polyester which should be modified with other materials until it improves its cell adhesion and hydrophilicity properties [1-5]. It has been generally accepted that extracellular matrix mimics may improve the attachment, proliferation, and viability of the cultured cells [6]. Electrospinning has been rapidly developed into a technique to prepare nanofibers with the diameter ranging from tens of nanometers to several microns [7-9]. The electrospun fibrous mats also show extremely high surface area and large porosity. Besides, the fibrous structure of the electrospun mats may mimic the extracellular matrix. It is well known that the collagen is a natural extracellular matrix component of nearly every tissue such as bone, skin, tendon, and ligament. Fiber diameters of the electrospun nanofibrous mats even approach that of collagen fiber bundles, between 50 and $500 \mathrm{~nm}$ [9]. Therefore, during the last few years, many works considering the tissue engineering of electrospun nanofibers have been reported. Most recently, electrospun nanofibers were prepared by Yang et al. and were applied in neural tissue engineering [10]. Although the presented nanofibers may mimic the morphologies of extracellular matrix to some extent, some modifications are still required to create a friendly environment for the cells attachment, proliferation, and functions such as communications. Some natural materials such as collagen 
and fibronectin and some peptides have been reported as scaffold modifiers [11, 12]. Controlling surface properties is very important for the high performance of adhesion. Biomaterials wettability is an important factor in the surface modification of materials. Surface modification of hydrophobic polymer surfaces can be achieved by wet (acid, alkali), dry (plasma), and radiation treatments (ultraviolet radiation and laser) [13-16]. Nonthermal and low-pressure plasma have been used in a series of surface treatment applications. The majority of plasma-assisted technologies are based on low-pressure processes [17]. The treatment of polymeric materials with plasma is a frequently used technique to accomplish surface modifications that affects chemical composition as well as surface topography. Moreover, microwave discharges are routinely employed in the processing of materials to deposit films as well as coatings $[18,19]$. In this study, the USS cells were used. The USSCs were first isolated from the umbilical cord blood in 2003 by Jager et al., and their differentiation capacity for transplantation was evaluated [20]. Kogler et al. (2004) also evaluated these cells for cytokine production. The USSCs are pluripotent, and also they are considered as the rare cell populations in umbilical cord blood. They have a high potential to proliferate and differentiate; thus, they are considered as valuable sources in cell therapy [21]. The USSCs are $\mathrm{CD}^{-} 5^{-}$, the adherent and HLA class II-negative stem cells with a long telomerase. Moreover, these cells possess a unique cytokine profile and have a high percentage of productions associated with self-renewing factors. In spite of other cord blood-derived mesenchymal cells, differentiated only into osteoblasts, chondrocytes, adipocytes [22], and neurons [21], the USSCs have the differentiation potential into osteoblasts, chondrocytes, blood cells, neurons, hepatocytes, and heart tissues under ex vivo conditions [21]. This cell expresses different factors, including adherent cells, growth factors, and various cytokines such as SCF, VEGF, GM-CSF, M-CSF, TGF-1, IL6, G-CSF, LIF, Flt3 ligand, TPO, HGF, SDF-1, IL-15, IL-12, IL-8, and IL-1, [22]. In this study, the coated collagen PHBV nanofibers were obtained through the plasma method. The samples were evaluated by ATR-FTIR, SEM and the contact angle as well as the cell culture with USSCs.

\section{Materials and Methods}

2.1. Nanofiber Preparation. A poly (3-hydroxybutyrate-co3-hydroxyvalerate) PHBV containing $5 \mathrm{~mol} \%$ of 3 -hydroxyvalerate with 680,000 molecular weight was purchased from Sigma Chemical Co. 2,2,2-trifluoroethanol (TFE) to prepare PHBV solution was also purchased from SigmaAldrich Chemicals and was used as received without further purification. An electrospinning apparatus used in this study was prepared by the Asia Nanomeghyas Company (Iran). The PHBV was dissolved at determined concentration in TFE. The PHBV solution $(2 \% \mathrm{w})$ in a glass syringe was controlled by the syringe pump. A positive high voltage source through a wire was applied at the tip of the syringe needle. In this situation, a strong electric field was generated between the PHBV solution and a collector. When the electric field reached a critical value with increasing voltage,

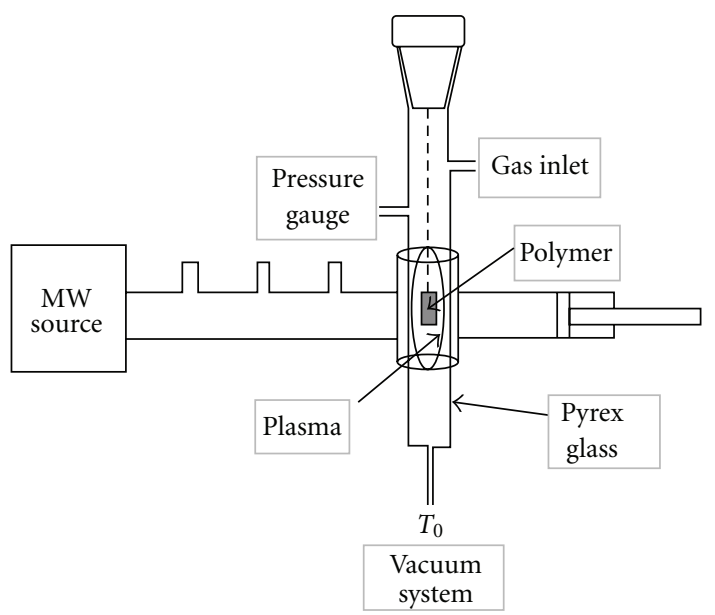

Figure 1: Experimental setup of microwave plasma.

the mutual charge repulsion overcame the surface tension of the polymer solution and the electrically charged jet was ejected from the tip of a conical shape as the Taylor cone. Ultrafine fibers were formed by the narrowing of the ejected jet fluid as it underwent increasing surface charge density due to the evaporation of the solvent. The electrospun PHBV nanofibrous mat was carefully detached from the collector and was dried in vacuo for 2 days at room temperature to remove solvent molecules completely. The used parameters for this nanofibers preparation can be seen in Table 1.

2.2. Plasma Treatment. In our current experimental observation, we used a microwave plasma source to modify the surface of the polystyrene samples. The microwave plasma has significant advantage over other techniques like Radio Frequency Glow Discharge (RFGD), frequently used in polymer surface modifications. Microwave sources could be operated at low pressures $\left(10^{-3}\right.$ to $\left.10^{-1} \mathrm{mbar}\right)$, which reduced the risk of gas phase contamination during processing. Moreover, the plasma properties could be controlled conveniently by adjusting the microwave power. Hence, the surface modification of this polymer became important. In this paper, we have demonstrated the effect of microwave plasma on the surface property of PHBV nanofibers with active gas (oxygen) at different times. Before exposure, the nanofibers were cut into $1 \times 1 \mathrm{~cm}$ sections. Then, they were placed within the ethanol solution for 24 hours to eliminate pollution and fats on the films. After removing the films from the solution, they were well washed in distilled water. The samples were placed in the plasma chamber and exposed to oxygen gas during 30 and $60 \mathrm{sec}$. The irradiated samples were investigated by structural analysis and microscopic and cellular investigations at times. The plasma surface treatment was reached in the microwave-induced plasma with a surface wave at $100 \mathrm{~W}$. The experimental setup has been shown in Figure 1.

2.3. Collagen Immobilization. Collagen (type I, from bovine Achilles tendon, purchased from Sigma) was immobilized onto the nanofiber surface based on the following protocol. 
TABLE 1: Used parameters for nanofibers preparation.

\begin{tabular}{lcccccc}
\hline $\begin{array}{l}\text { Syringe } \\
\text { Diameter }(\mathrm{mm})\end{array}$ & $\begin{array}{c}\text { Dram speed } \\
(\mathrm{rpm})\end{array}$ & $\begin{array}{c}\text { Injected speed } \\
(\mathrm{mL} / \mathrm{min})\end{array}$ & $\begin{array}{c}\text { Syringe tip } \\
\text { distance to } \\
\text { deram }(\mathrm{mm})\end{array}$ & Voltage $(\mathrm{kv})$ & $\begin{array}{c}\text { Temperature } \\
\left({ }^{\circ} \mathrm{C}\right)\end{array}$ & Time (h) \\
\hline 17 & 1000 & 2 & 75 & 20 & 30 & 7 \\
\hline
\end{tabular}

A weighted amount of the plasma modified nanofibrous mat was rinsed with acetic acid buffer solution (50 mM, pH: 5). Then, the radiated mat was submerged into the collagen solution $(15 \mathrm{mg} / \mathrm{mL}$ in acetic acid solution, $50 \mathrm{mM}, \mathrm{pH}: 5)$ and was shaken gently for $2 \mathrm{~h}$ at $50^{\circ} \mathrm{C}$. The obtained samples were placed inside a vacuum oven so that they would fully lose humidity.

2.4. Fourier Transmission Infrared Spectroscopy. The samples were examined by FTIR (Bruker-Equinox 55; Bruker Optics, Billerica, Mass) before and after adjustment. The samples were scratched into powder and were produced as capsules using $\mathrm{KBr}$ and, then, were put to investigation.

2.5. Scanning Electron Microscopy. The surface characteristics of various modified and unmodified films were studied by scanning electron microscopy (SEM; Cambridge Stereoscan, model S-360; Cambridge Instruments, Wetzlar, Germany) to analyze the changes in the surface morphology. The films were first coated with a gold layer (Joel fine coat, ion sputter for 2 hours) to provide surface conduction before their scanning.

2.6. Contact Angle Analysis. The sample surfaces static contact angles were investigated by a contact-angle-measuring device (Krüss G10; Krüss, Matthews, NC) following the sessile drop method.

\subsection{Cellular Analysis}

2.7.1. Culture and Isolation of the USSC from Fresh Umbilical Cord Blood. After consent from mothers, their umbilical cords were obtained from the cord vein. Only $40 \%$ of the cord blood samples contained USSCs. The mean age of donors was 28 years. After collecting the samples, the red blood cells were lysed using ammonium chloride $\left(\mathrm{NH}_{4} \mathrm{CL}\right)$ and the isolation procedure continued by Ficoll. Then the samples were rinsed twice with sterile phosphate-buffered saline $(\mathrm{pH}$ 7.4). After centrifuging, the resultant cells were placed in Dulbecco's modified Eagle's medium (DMEM) low glucose, which had been enriched with $100 \mathrm{nmol}$ dexamethasone, $10 \%$ fetal bovine serum (FBS), penicillin, and streptomycin. The first medium exchange process was done for 24 hours, then every 4 days. When $80 \%$ of the flask surface area was covered by the cells, the cells were passed by using $0.25 \%$ trypsin and ethylenediaminetetraacetic acid (EDTA). The USSCs were regularly expanded on the culture medium; and the $37^{\circ} \mathrm{C}$ temperature and $5 \%$ of $\mathrm{CO}_{2}$ were required for the growth. The USSCs were first trypsinized and counted. The tubes, containing $10^{5}-10^{6}$ cells, were incubated on a rocker rotator for 10 to 6 hours and centrifuged at $1000 \mathrm{rpm}$ for 6 minutes, and 3\% human serum was added to cell deposition thereafter. The resultant mixture remained at room temperature for 30 minutes. The cells were again centrifuged as above, and the PBS was added to the cell deposition. The cell mixture was passed through a nylon mesh, and then $100 \mu \mathrm{L}$ of cells was added to each tube with the following antibodies: anti-CD90, anti-CD105, antiCD166, anti-CD45, anti-CD73, and anti-CD34. Next, they were kept at $4^{\circ} \mathrm{C}$ out of light for 45 minutes. After washing, the cells were fixed in $100 \mu \mathrm{L}$ of $1 \%$ paraformaldehyde. Finally, the flow cytometric analysis was carried out. The karyotype analysis was performed on USSC. The first and last passages were chosen for karyotype analysis. The cells were first placed in an incubator with $0.1 \mu \mathrm{g} / \mathrm{mL}$ colcemid for 3 to 4 hours. Next, they were trypsinized, and 0.075 of $\mathrm{M}$ KCL solution was added. The cells were incubated with $5 \%$ $\mathrm{CO}_{2}$ at $37^{\circ} \mathrm{C}$ for 20 minutes. In the next stage, methanol and acetic acids in ratio of $1: 3$ were added for fixing the samples. Finally, the cells were scattered over the slide surface, and the chromosomes were subjected to karyotype analysis.

2.7.2. Cell Culture Study on the Polymer Surface. The tissue culture polystyrenes (TCPSs) as control samples were well cleaned and sterilized by the autoclave method. Individual samples were placed in Petri dishes using a sterilized pincer; the USSC suspension was transferred to a flask $(25 \mathrm{~cm})$ containing DMEM, $2 \mathrm{mML}$-glutamine, penicillin $(100 \mu \mathrm{L} / \mathrm{mL})$, streptomycin $(100 \mu \mathrm{L} / \mathrm{mL})$, and FBS $10 \%$. The suspension was then placed in an incubator $\left(5 \% \mathrm{CO}_{2}\right.$, $37^{\circ} \mathrm{C}$ ). The USSCs were proliferated in the flask and were washed using the PBS. Then the trypsin enzyme/EDTA was added to the flask $\left(37^{\circ} \mathrm{C}\right)$, and the flask was incubated for 2 minutes. The culture media (FBS/DMEM) was added to the flask, and the cells were gently pipetted. The cell suspension was transferred to a falcon tube $(15 \mathrm{~mL})$ and centrifuged $(1410 \mathrm{rpm})$ for 5 minutes. The solution was removed and the precipitation was transferred to a new flask $(75 \mathrm{~cm})$ for reculturing. Pieces of cell culture $(1 \times$ $1 \mathrm{~cm}$ ) from the petri dish (control) and the main sample were placed individually in one of the Petri dish wells by using a sterilized pincer. 100,000 cells/well were seeded into a 24-well culture plate removed by pipette and poured onto the control and the main samples. Then all samples were placed in Memmert incubator at $37^{\circ} \mathrm{C}$ for 48 hours and studied using a ceti microscope (Wolf Laboratories, UK). Cell proliferation was determined by the MTT assay for viable cell numbers. The MTT tetrazolium compound was reduced by living cells in a colored formazan product that was soluble in the tissue culture medium. The quantity of formazan product was directly proportional to the number of viable cells in the culture. The assays were performed by 


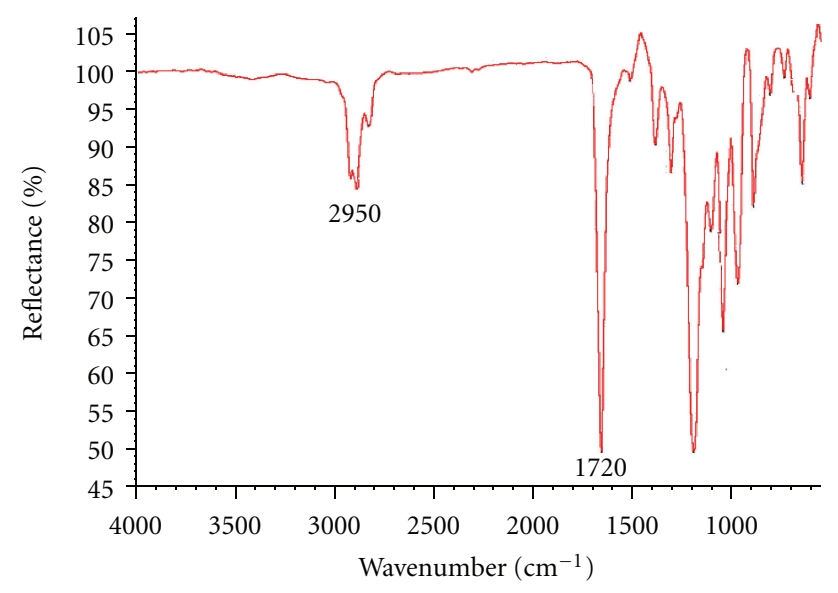

FIGURE 2: FTIR analysis of uncoated nanofiber film.

adding $20 \mu \mathrm{L}$ of MTT solution (Sigma-Aldrich) and $200 \mu \mathrm{L}$ of fresh medium to each well after aspirating the spent medium and incubating at $37^{\circ} \mathrm{C}$ for 4 hours with protection from light. Colorimetric measurement of formazan dye was performed at a wavelength of $570 \mathrm{~nm}$ using a Rayto microplate reader.

\section{Results}

3.1. FTIR Results. The results, from the ATR-FTIR spectrum of the uncoated nanofiber sample, the collagen film, and the nanofiber sample modified with collagen, have been shown in Figures 2-4. In Figure 2, the strong band in $1720 \mathrm{~cm}^{-1}$ has been shown to be related to the $\mathrm{C}=\mathrm{O}$ group. The stretching band in $800-975 \mathrm{~cm}^{-1}$ has been shown to be related to the $-\mathrm{C}-\mathrm{O}-\mathrm{C}-\mathrm{O}$ group, and the stretching band in $2800-3000 \mathrm{~cm}^{-1}$ has been shown to be related to the $-\mathrm{CH}_{3}$ groups.

Figure 3 illustrates the ATR-FTIR spectra of collagen film. The spectra show the strong band in $1720 \mathrm{~cm}^{-1}$ as related to the $\mathrm{C}=\mathrm{O}$ group and stretching bands in $2900-3000 \mathrm{~cm}^{-1}$ as related to the $-\mathrm{CH}_{3}$ groups. The stretching bands in $3318 \mathrm{~cm}^{-1}$ and $3746 \mathrm{~cm}^{-1}$ are related to the $\mathrm{OH}$ and $\mathrm{NH}$ groups.

Figure 4 also shows the strong band in $1720 \mathrm{~cm}^{-1}$ as related to the $\mathrm{C}=\mathrm{O}$ group, the stretching band in 800 $975 \mathrm{~cm}^{-1}$ as related to the $-\mathrm{C}-\mathrm{O}-\mathrm{C}-$ group, and the stretching bands in $2800-3000 \mathrm{~cm}^{-1}$ as related to the $-\mathrm{CH}_{3}$ groups. The stretching bands in $3429 \mathrm{~cm}^{-1}$ and $3783 \mathrm{~cm}^{-1}$ are related to the $\mathrm{OH}$ and $\mathrm{NH}$ groups due to the presence of collagen.

3.2. SEM Investigations. Figures 5 and 6 show the electron microscopy images of the uncoated and the coated nanofibers with collagen in different magnifications. Figure 5 shows the nanofiber mat prepared by the electrospinning method of different magnifications ((a) 5000×, (b) 10000× and, (c) $20000 \times$ ).

Figure 6 shows the collagen-coated nanofiber mat prepared by the electrospinning method of different magnifications ((a) 5000×, (b) $10000 \times$, and (c) 20000x).

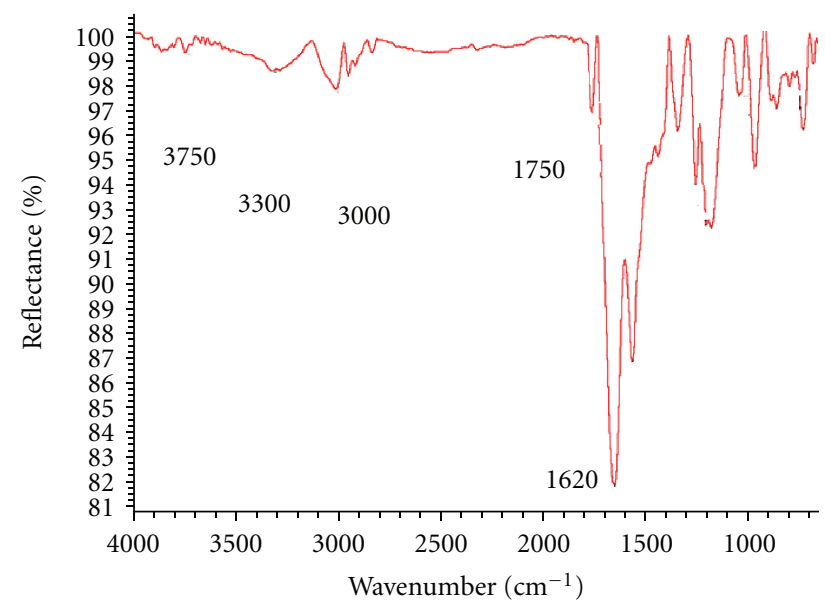

Figure 3: FTIR analysis of collagen film.

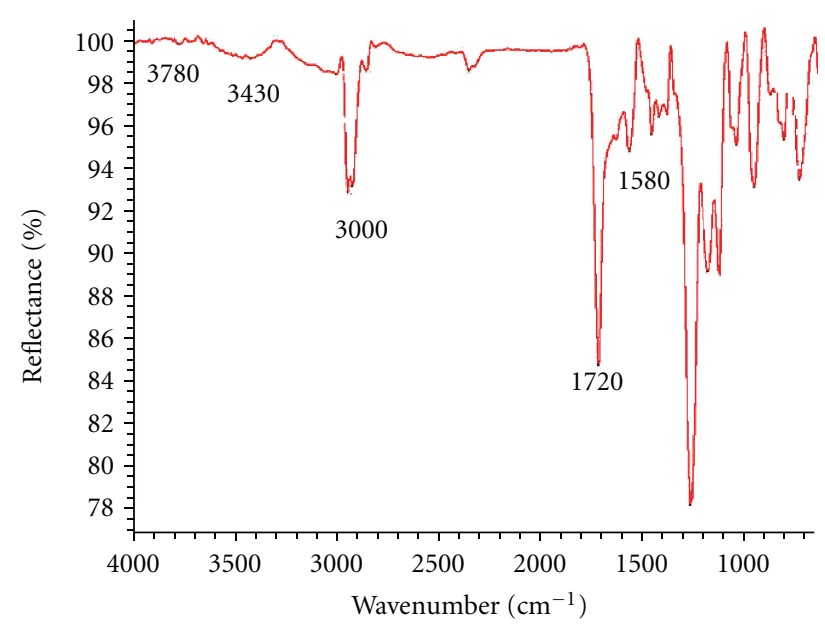

FIGURE 4: FTIR analysis of coated nanofiber film.

TABLe 2: Contact angle for uncoated and coated collagen nanofibers.

\begin{tabular}{cccc}
\hline $\mathrm{T}\left({ }^{\circ} \mathrm{C}\right)$ & $\begin{array}{c}\text { PHBV nanofiber } \\
\theta(\mathrm{deg})\end{array}$ & $\begin{array}{c}\text { Coated collagen } \\
\text { nanofiber } \\
\text { (treated plasma at } \\
30 \mathrm{~s}) \theta(\mathrm{deg})\end{array}$ & $\begin{array}{c}\text { Coated collagen } \\
\text { nanofiber }\end{array}$ \\
\hline 25 & $67 \pm 3.2^{\circ}$ & $58 \pm 1.9^{\circ}$ & $60 \mathrm{~s}) \theta(\mathrm{deg})$ \\
\hline
\end{tabular}

3.3. Contact Angle Results. Table 2 shows the contact angle obtained for the uncoated and the coated collagen nanofibers. The contact angles of $67^{\circ}$ and $56-58^{\circ}$ were obtained for the uncoated and the coated nanofibers, respectively. The $10^{\circ}$ difference in the contact angle, obtained for the 2 samples, shows a better hydrophilicity of the collagencoated nanofibers than the uncoated nanofibers.

3.4. Cellular Study. Table 3 shows the MTT assay for TCPS (control), the uncoated nanofiber, and the coated collagen nanofiber samples by plasma in different times. The results showed a high viability for the samples of the uncoated 


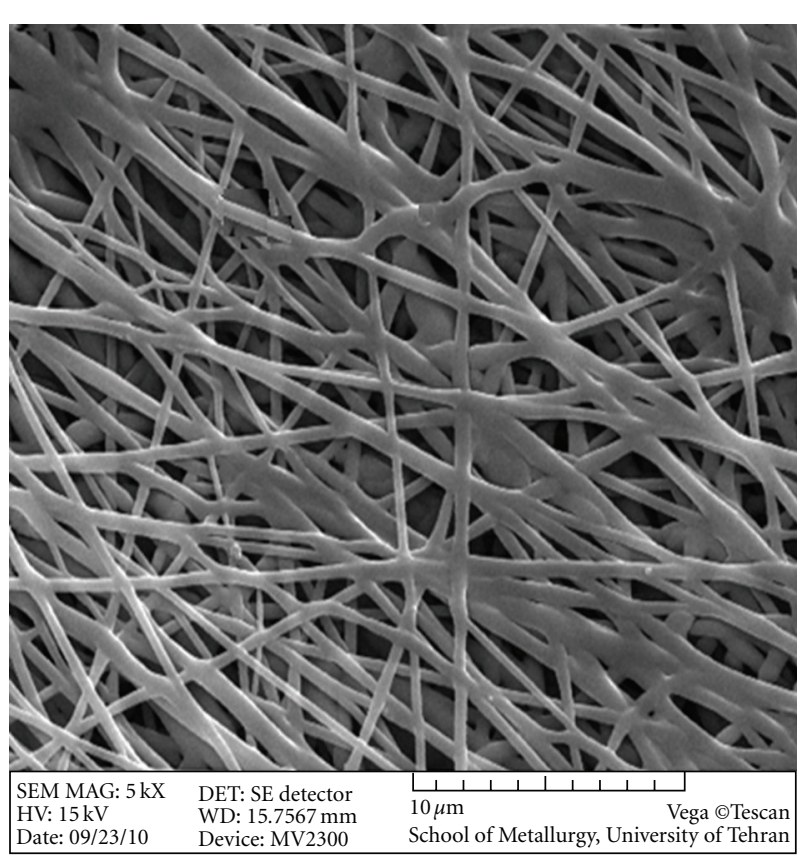

(a)

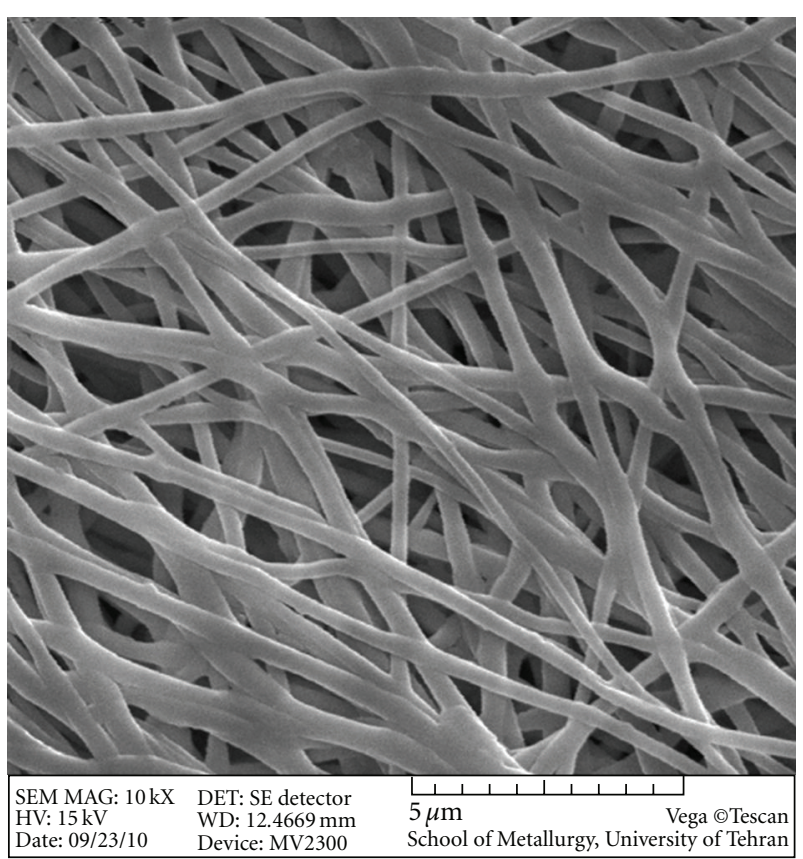

(b)

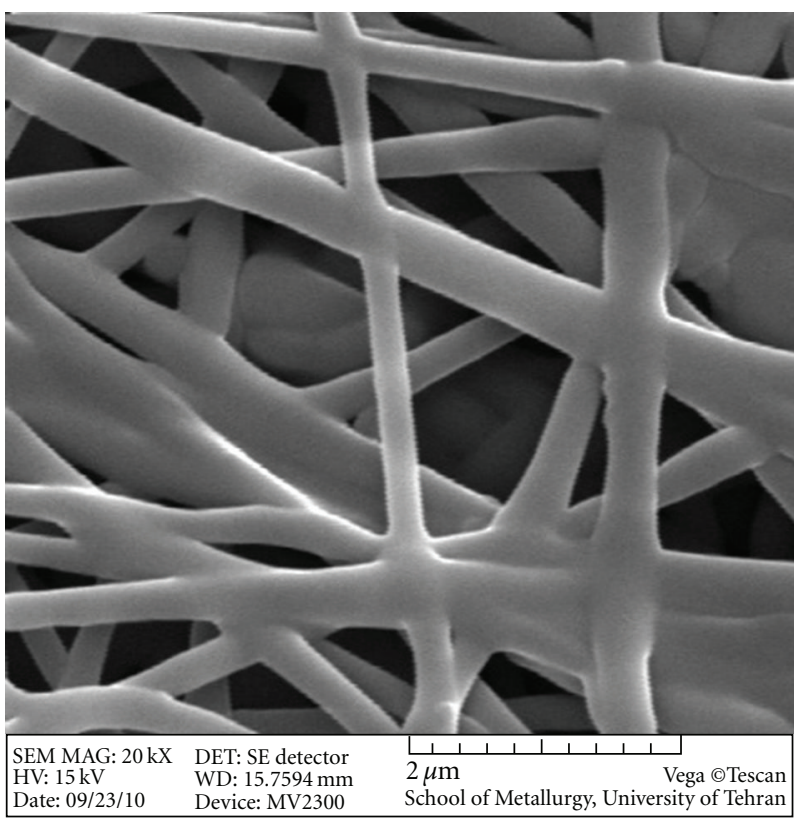

(c)

FIgURE 5: SEM images of PHBV nanofibers in different magnifications ((a) 5000×, (b) $10000 \times$, and (c) $20000 \times$ ).

nanofiber and the collagen-coated nanofiber by plasma in the different times of 30 and 60 seconds $(112,130$, and $164 \%$ resp.). Figure 7 shows images of the cell culture on the nanofibers and the control sample. Image (a) is related to the control sample and images (b), (c), and (d) are related to the uncoated nanofiber and the collagen-coated nanofiber by plasma in the different times of 30 and $60 \mathrm{~s}$.

\section{Discussion}

ATR-FTIR structural analysis showed successfully the presence of collagen on the nanofiber surfaces. The smooth and homology nanofibers have been clearly shown in the figures. The size average was obtained for the normal nanofibers to be about $280 \mathrm{~nm}$. The smooth and homology 


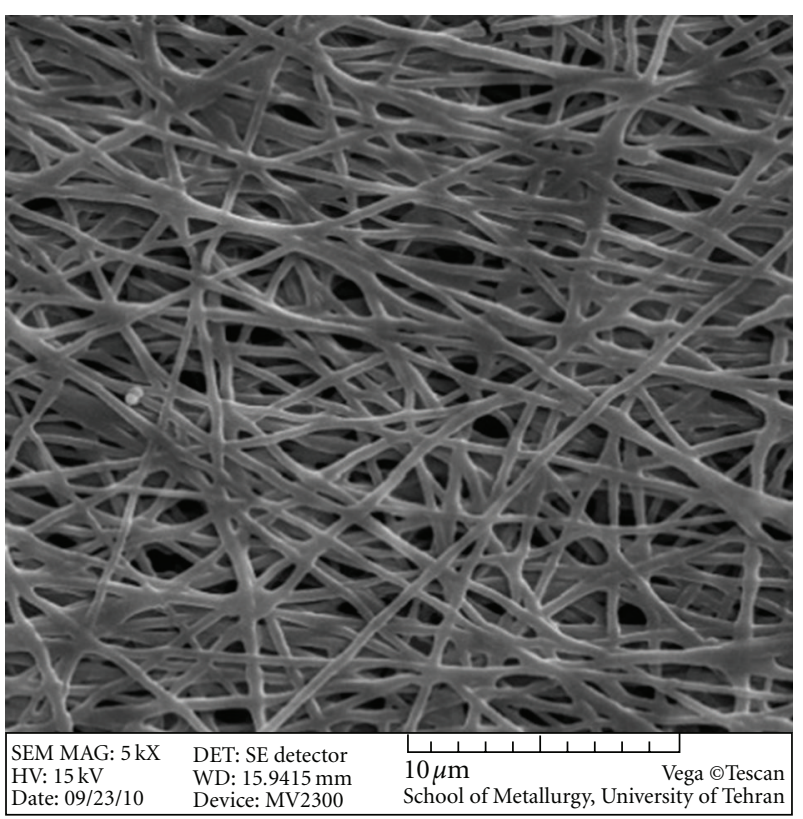

(a)

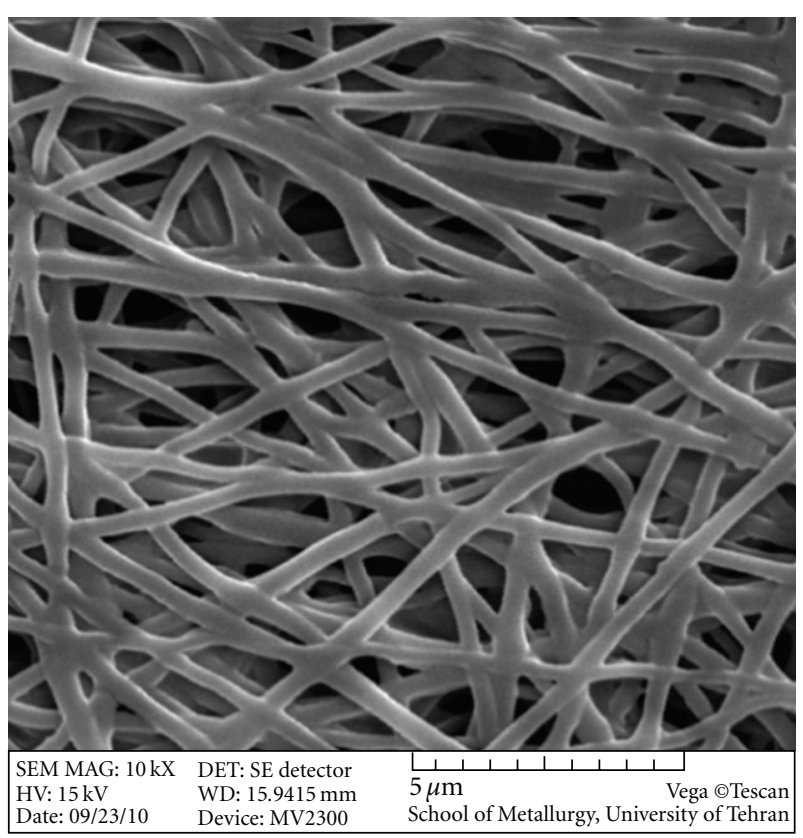

(b)

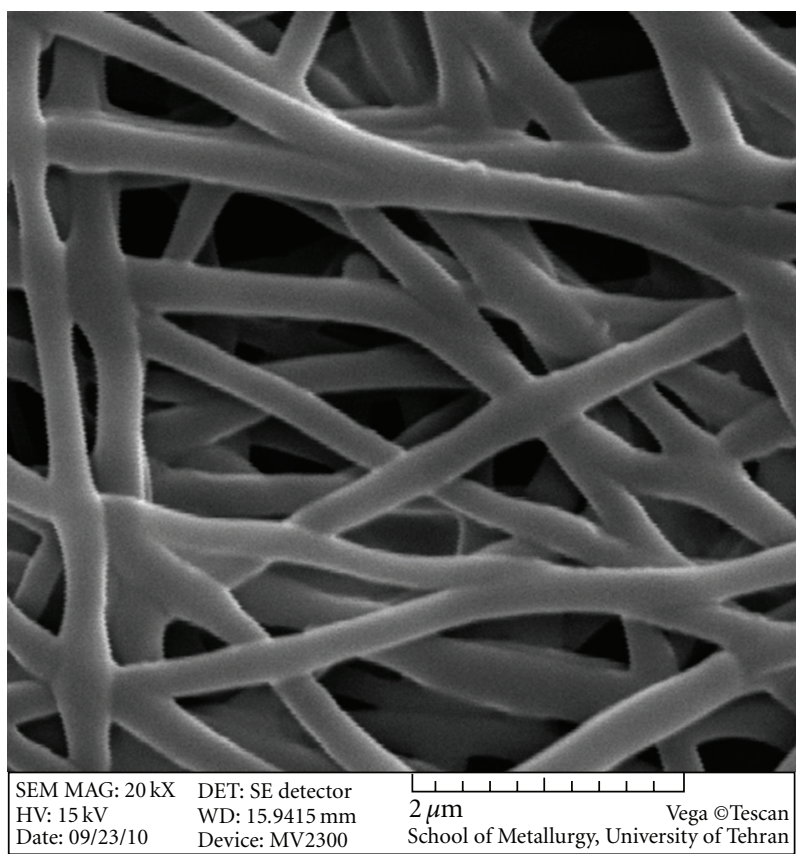

(c)

FIGURE 6: SEM images of coated collagen PHBV nanofibers in different magnifications ((a) 5000×, (b) $10000 \times$, and (c) $20000 \times$ ).

modified nanofibers have been clearly shown in the figures. The size average was obtained for the modified nanofibers to be about $400 \mathrm{~nm}$, whose increasing is due to collagen coated on the PHBV surfaces. The $10^{\circ}$ of difference in the contact angle, obtained for the two samples (normal and modified nanofibers), shows a better hydrophilicity of the collagen-coated nanofibers than of the uncoated nanofibers.
The results showed a high viability for the samples of the uncoated nanofiber and the collagen-coated nanofiber by plasma in the different times of 30 and 60 second but the collagen-coated nanofiber by plasma in $60 \mathrm{~s}$ showed a better viability than the uncoated nanofiber and the radiated sample in $30 \mathrm{~s}$. Also, these samples caused more cells to proliferate. Cellular images showed well growth in 


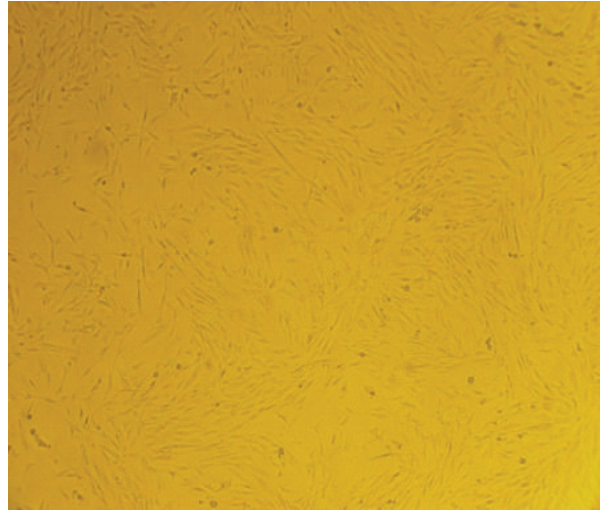

(a)

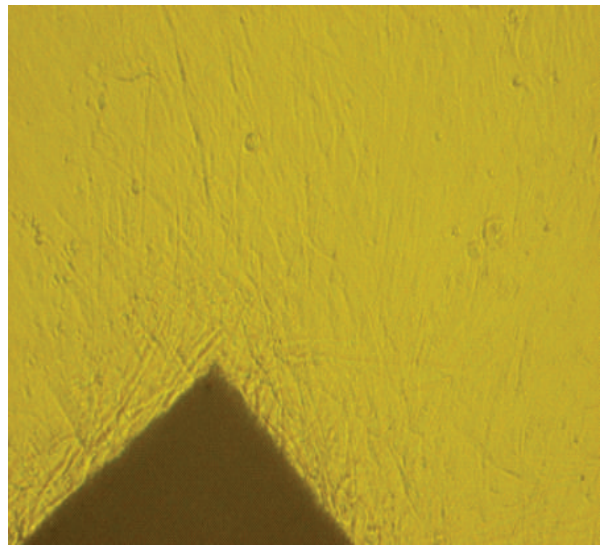

(c)

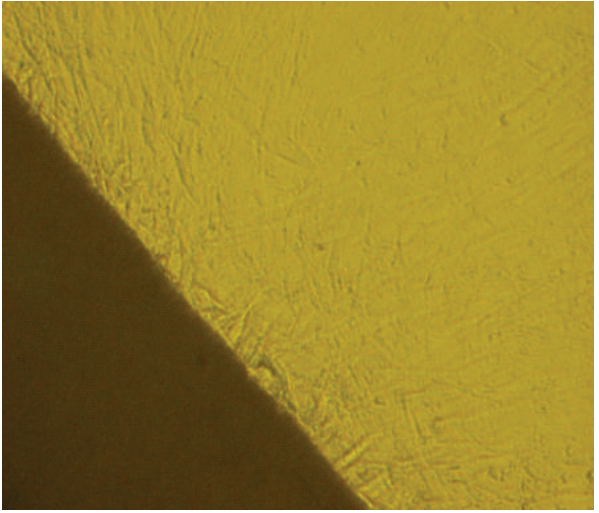

(b)

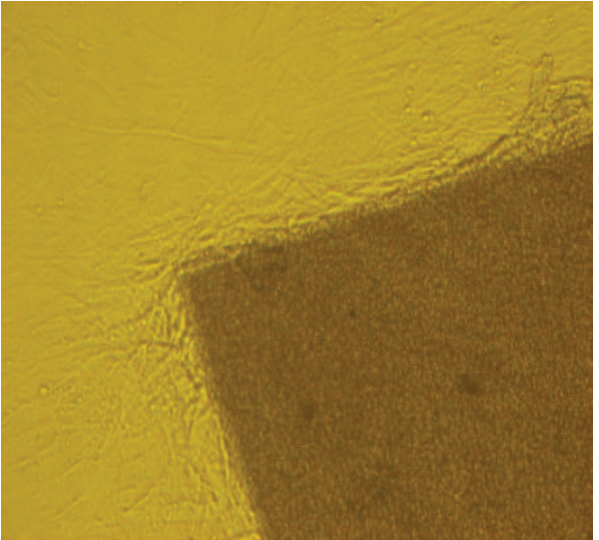

(d)

Figure 7: USS cell growth on the samples. (a) Control (TCPS), (b) uncoated nanofiber, (c) coated nanofiber (modified by plasma, 30 s), and (d) coated nanofiber (modified by plasma, $60 \mathrm{~s}$ ).

TABLE 3: MTT analysis of the samples.

\begin{tabular}{lcc}
\hline Sample & $\lambda(\mathrm{nm})$ & Viability \% \\
\hline TCPS & 606 & 100 \\
PHBV nanofiber & 677 & 112 \\
$\begin{array}{l}\text { PHBV nanofiber (coated collagen } \\
\text { nanofiber by oxygen plasma) (30 }\end{array}$ & 792 & 130 \\
$\begin{array}{l}\text { seconds) } \\
\begin{array}{l}\text { PHBV nanofiber (coated collagen } \\
\text { nanofiber by oxygen plasma) (60 } \\
\text { seconds) }\end{array}\end{array}$ & 999 & 164 \\
\hline
\end{tabular}

the vicinity of nanofibers especially the collagen-coated nanofiber.

\section{Conclusions}

PHBV nanofibers with an average size of about $280 \mathrm{~nm}$ were designed and successfully coated with collagen by the plasma methods shown in the analysis. A $10^{\circ}$ difference in the contact angle, obtained for the 2 samples, showed a better hydrophilicity of the collagen-coated nanofibers than the uncoated ones. Cellular investigations showed better adhesion, growth, and viability in the collagencoated nanofibers than in the uncoated nanofibers. These collagen-coated nanofibers could be used well for tissue engineering.

\section{References}

[1] S. F. Williams, D. P. Martin, D. M. Horowitz, and O. P. Peoples, "PHA applications: addressing the price performance issue I. Tissue engineering," International Journal of Biological Macromolecules, vol. 25, no. 1-3, pp. 111-121, 1999.

[2] J. Liu, B. Zhao, Y. Zhang, Y. Lin, P. Hu, and C. Ye, "PHBV and predifferentiated human adipose-derived stem cells for cartilage tissue engineering," Journal of Biomedical Materials Research-Part A, vol. 94, no. 2, pp. 603-610, 2010.

[3] W. Meng, SE. Y. Kim, J. Yuan et al., "Electrospun $\mathrm{PHBV/collagen} \mathrm{composite} \mathrm{nanofibrous} \mathrm{scaffolds} \mathrm{for} \mathrm{tissue}$ engineering," Journal of Biomaterials Science, Polymer Edition, vol. 18, no. 1, pp. 81-94, 2007.

[4] A. Ndreu, L. Nikkola, H. Ylikauppilar, N. Ashammakhi, and V. Hasirci, "Electrospun biodegradable nanofibrous mats for tissue engineering," Nanomedicine, vol. 3, no. 1, pp. 45-60, 2008. 
[5] G. Torun Köse, F. Korkusuz, A. Özkul, S. Ber, H. Kenar, and V. Hasirci, "Tissue engineering of bone using collagen and PHBV matrices," Technology and Health Care, vol. 10, no. 3-4, pp. 299-301, 2002.

[6] C. Gerard, C. Catuogno, C. Amargier-Huin et al., "The effect of alginate, hyaluronate and hyaluronate derivatives biomaterials on synthesis of non-articular chondrocyte extracellular matrix," Journal of Materials Science: Materials in Medicine, vol. 16, no. 6, pp. 541-551, 2005.

[7] D. Li and Y. Xia, "Electrospinning of nanofibers: reinventing the wheel?" Advanced Materials, vol. 16, no. 14, pp. 1151-1170, 2004.

[8] Z. M. Huang, Y. Z. Zhang, M. Kotaki, and S. Ramakrishna, "A review on polymer nanofibers by electrospinning and their applications in nanocomposites," Composites Science and Technology, vol. 63, no. 15, pp. 2223-2253, 2003.

[9] L. A. Smith and P. X. Ma, "Nano-fibrous scaffolds for tissue engineering," Colloids and Surfaces B: Biointerfaces, vol. 39, no. 3, pp. 125-131, 2004.

[10] F. Yang, R. Murugan, S. Wang, and S. Ramakrishna, "Electrospinning of nano/micro scale poly(l-lactic acid) aligned fibers and their potential in neural tissue engineering," Biomaterials, vol. 26, no. 15, pp. 2603-2610, 2005.

[11] T. Ito, T. Nakamura, K. Suzuki et al., "Regeneration of hypogastric nerve using a polyglycolic acid (PGA)-collagen nerve conduit filled with collagen sponge proved electrophysiologically in a canine model," International Journal of Artificial Organs, vol. 26, no. 3, pp. 245-251, 2003.

[12] T. A. Kapur and M. S. Schoichet, "Chemically-bound nerve growth factor for neural tissue engineering applications," Journal of Biomaterials Science, Polymer Edition, vol. 14, no. 4, pp. 383-394, 2003.

[13] H. W. Lu, Q. H. Lu, W. T. Chen, H. J. Xu, and J. Yin, "Cell culturing on nanogrooved polystyrene petri dish induced by ultraviolet laser irradiation," Materials Letters, vol. 58, no. 1-2, pp. 29-32, 2004.

[14] V. Roucoules, F. Gaillard, T. G. Mathia, and P. Lanteri, "Hydrophobic mechano chemical treatment of metallic surfaces. Wettability measurements as a means of assessing homogeneity," Advances in Colloid and Interface Science, vol. 97, no. 1-3, pp. 177-201, 2002.

[15] K. M. Hay, M. I. Dragila, and J. Liburdy, "Theoretical model for the wetting of a rough surface," Journal of Colloid and Interface Science, vol. 325, no. 2, pp. 472-477, 2008.

[16] U. Kogelschatz, "Dielectric-barrier discharges: their history, discharge physics, and industrial applications," Plasma Chemistry and Plasma Processing, vol. 23, no. 1, pp. 1-46, 2003.

[17] A. I. Kuzmichev, "Ion plasma sources based on a microwave oven," Instruments and Experimental Techniques, vol. 37, pp. 648-653, 1994.

[18] V. Asmussen, "electron cyclotron resonance microwave discharge for etching and thin film deposition," Journal of Vacuum Science \& Technology, vol. 7, pp. 883-889, 1989.

[19] C. Takahashi, Y. Jin, K. Nishimura, and S. Matsuo, "Anisotropic etching of Si and WSiN using ECR plasma of SFCF gas mixture," Japanese Journal of Applied Physics, vol. 39, no. 6, pp. 3672-3676, 2000.

[20] M. Jager, M. Sager, A. Knipper et al., "In vivo and in vitro bone regeneration from cord blood derived mesenchymal stem cellsIn-vitro- und in-vivo-knochenregenerierung durch mesenchymale stammzellen aus dem nabelschnurblut," Orthopade, vol. 33, no. 12, pp. 1361-1372, 2004.
[21] G. Kogler, S. Sensken, J. A. Airey et al., "A new human somatic stem cell from placental cord blood with intrinsic pluripotent differentiation potential," Journal of Experimental Medicine, vol. 200, no. 2, pp. 123-135, 2004.

[22] G. Kogler, T. F. Radke, A. Lefort et al., "Cytokine production and hematopoiesis supporting activity of cord blood-derived unrestricted somatic stem cells," Experimental Hematology, vol. 33, no. 5, pp. 573-583, 2005. 

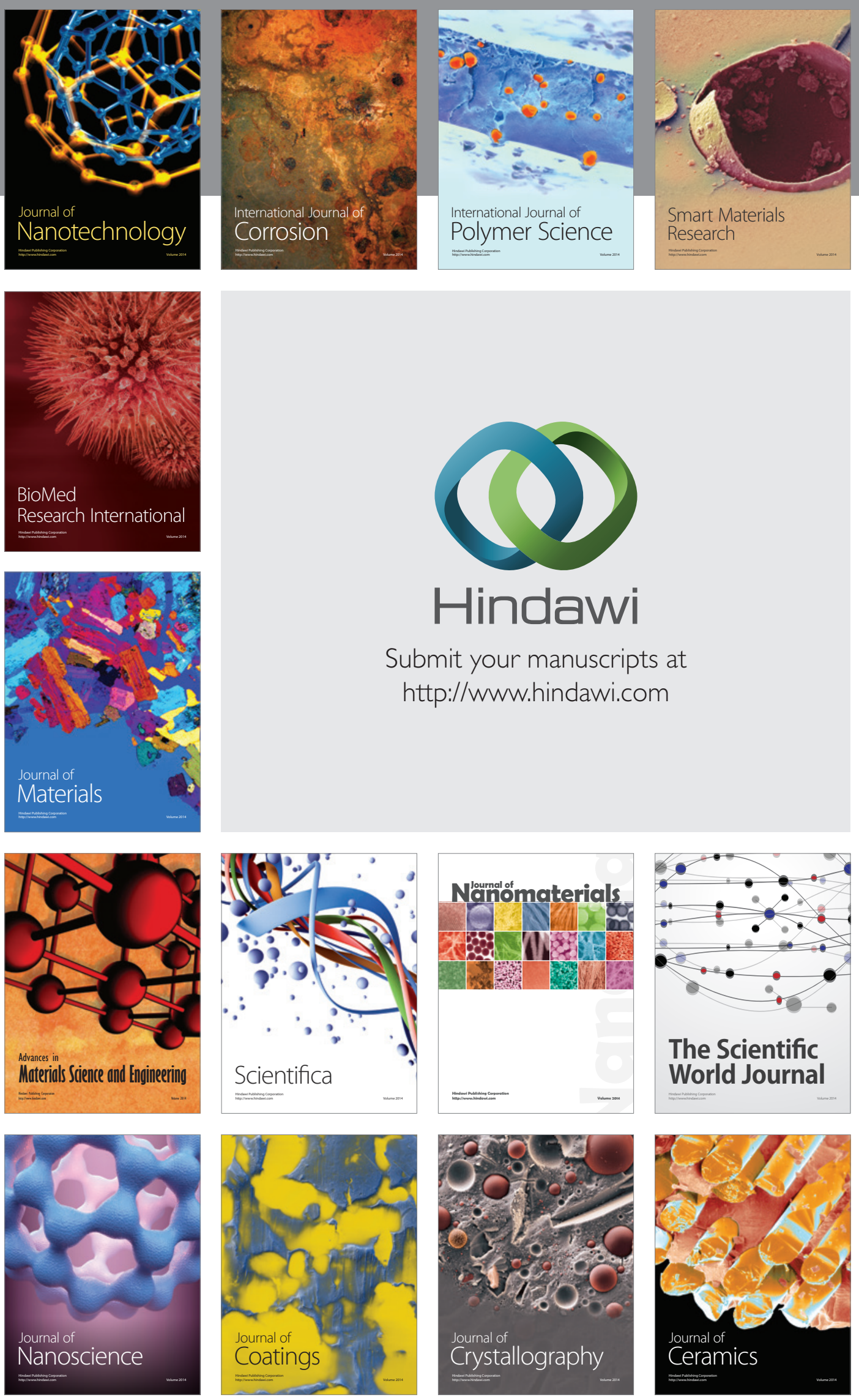

The Scientific World Journal

Submit your manuscripts at

http://www.hindawi.com

\section{World Journal}

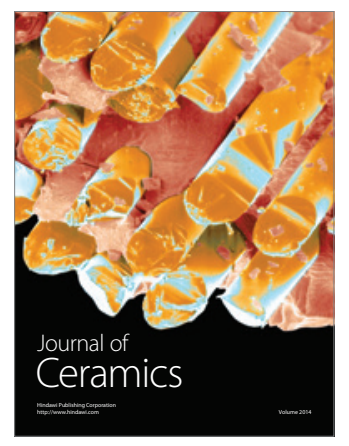

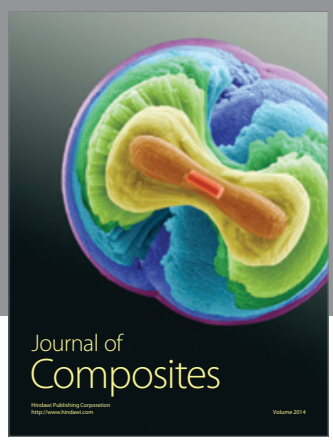
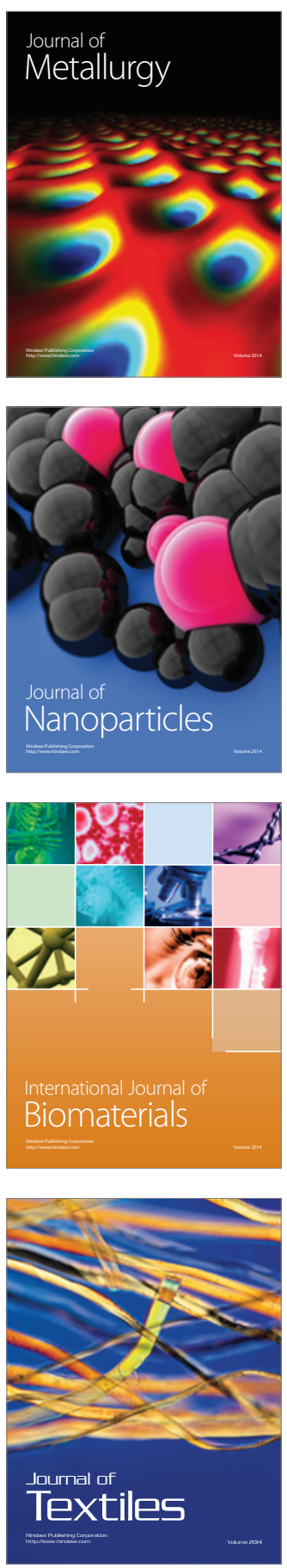